\title{
Effect of hemodialysis and peritoneal dialysis on redox status in chronic renal failure patients: a comparative study
}

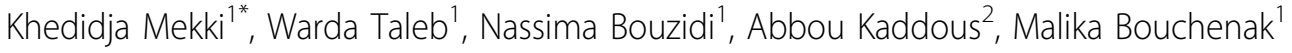

\begin{abstract}
Objective: To investigate the effects of hemodialysis (HD) and periotoneal dialysis (PD) on oxidative stress in chronic renal failure patients (CRF).

Methods: $20 \mathrm{HD}$ patients (M/F: 8/12, $36 \pm 12$ years) and 20 PD patients (M/F: 10/10, $40 \pm 8$ years) were compared with 20 end stage renal failure patients (CRF) (M/F: 4/16, $61 \pm 13$ years).

Results: Thiobarbituric acid reactive substances (TBARS) values were elevated in HD and decreased in PD compared to CRF $(P<0.05)$. TBARS-VLDL and TBARS-HDL 2 were decreased in $H D$ and $P D$, compared to CRF $(p<0.05)$. TBARS-LDL were higher in HD compared to CRF $(p<0.05)$. No significant difference in TBARS-HDL 3 values between the three groups. Carbonyls were increased in HD $(p<0.05)$ and PD $(p<0.01)$ compared to CRF. Plasma superoxide dismutase activity (SOD) was decreased in HD compared to CRF and PD $(P<0.05)$. Glutathion peroxidase activity (GSH-Px) was decreased in HD and PD ( $<<0.005)$, compared to CRF. Decrease in catalase activity was noted only in PD compared to CRF $(P<0.05)$. An increase in nitric oxide was noted in HD compared to CRF $(p<0.05)$. Albumin concentrations were higher in HD and PD compared to CRF $(P<0.001)$. Whereas uric acid concentrations were decreased in HD ( $<0.001)$ compared to CRF and PD. Bilirubin values were similar in all groups. Increased values of iron were noted in HD and PD, compared to PD $(p<0.001)$.

Conclusion: HD and PD aggravate oxidative stress generated by uremia. HD accentuates lipid and protein peroxidation, while PD aggravates protein oxidation. However, the activity of antioxidant enzymes was altered by both dialysis treatments.
\end{abstract}

\section{Introduction}

Despite significant progress in dialysis technology, atherosclerosis and cardiovascular diseases (CVD) are the leading causes of morbidity and mortality in patients receiving renal replacement therapy (RRT). The estimated risk for cardiac events such as myocardial infarction is 3.5-50 times higher among patients requiring RRT than in the general population [1]. High rate of CVD morbidity and mortality in chronic renal failure (CRF) was attributed to a higher prevalence of both classical and nontraditional risk factors. Moreover, uremia itself contributes to cardiac pathology: many studies show that CRF is an independent risk factor for $\mathrm{CV}$

\footnotetext{
* Correspondence: khmekki@hotmail.com

'Laboratoire de Nutrition Clinique et Métabolique, Département de Biologie, Faculté des Sciences, Université d'Oran 31100, Algérie

Full list of author information is available at the end of the article
}

morbidity and mortality even after adjustment for traditional and nontraditional risk factors [2]. The classical risk factors for CVD (such as old age, hypertension, diabetes, smoking, dyslipidaemia, left ventricular hypertrophy, heart failure and physical inactivity) are overrepresented in patients on RRT [2-4].

In recent years, oxidative stress (OS) has been postulated to be an important risk factor for cardiovascular disorders [5]. OS results from an imbalance between oxidant production and antioxidant defence mechanisms with increased levels of pro-oxidants leading to tissue damage [6]. Antioxidants can be divided into intracellular and extracellular antioxidants. Intracellular enzymatic antioxidants are superoxide dismutase (SOD), catalase, and glutathione peroxidase, which convert substrates (superoxide anion radicals and hydrogen peroxide) to less reactive forms. Several extracellular antioxidants, 
such as albumin, bilirubin and urate, prevent free radical reaction by sequestering transition metal ions by chelation in plasma [6].

Several studies have demonstrated increased oxidative stress in patients with CRF, including accumulation of reactive carbonyl compounds as markers of elevated protein peroxidation $[5,7,8]$, increased concentrations of thiobarbituric acid-reactive substances and malondialdehyde in plasma as markers of high lipid peroxidation [9-11].

One reason for OS in patients with renal failure is the underlying disease itself. Renal toxicity and immunological disorders of the kidney result in an elevated formation of reactive oxygen species (ROS) active in the pathogenesis of kidney disease. However, treatment procedures were also shown to induce OS. Oxidative stress is particularly detrimental in patients receiving hemodialysis (HD) because there is massive and repeated at each dialysis session due to the contact of blood with dialysis membranes, facing to a chronic deficit in antioxidant defense system (8). Moreover, Several lines of evidence have indicated that oxidative metabolism in peripheral and peritoneal phagocytes is activated during peritoneal dialysis (PD) with conventional dialysate characterized by high concentration of glucose, by glucose degradation products (GDP), and by low $\mathrm{pH}$ and high osmolality [12]. Bioincompatibility of PD solutions seems to play a central role in the increase of ROS production [13].

Moreover, It had been hypothesized that a deficiency of vascular nitric oxide (NO) might be involved in the accelerated atherosclerosis and dramatic cardiovascular mortality observed in patients with CRF [14]. Endothelial dysfunction defined as the impaired ability of vascular endothelium to stimulate vasodilation, plays a key role in the development of atherosclerosis in CRF. The major cause of the endothelial dysfunction is decreased bioavailability of NO, a potent biological vasodilator produced in vascular endothelium from L-arginine by the endothelial NO synthase (eNOS). Another important role of endothelial NO is the protection of the vascular wall from the OS induced by its own metabolic products and by the oxidation products of lipids and lipoproteins [15].

Thus, this study was carried out in order to investigate the effects of hemodialysis (HD) and periotoneal dialysis (PD) on lipid peroxidation and protein oxidation and antioxidant defence in patients with chronic renal failure (CRF).

\section{Subjects and Methods}

The study was carried out on $60 \mathrm{CRF}$ patients. They included 20 end-stage renal failure patients (CRF), 20 HD patients and $20 \mathrm{PD}$ patients (Table 1 ). In the selection of the CRF patients, we excluded all those with
Table 1 Clinical and biochemical characteristics of the patients

\begin{tabular}{lccc}
\hline & CRF & HD & PD \\
\hline Patients & $\mathrm{N}=20$ & $\mathrm{~N}=20$ & $\mathrm{~N}=20$ \\
\hline Age (years) & $61 \pm 13$ & $36 \pm 12$ & $40 \pm 8$ \\
\hline Weight $(\mathrm{kg})$ & $71.5 \pm 8.07$ & $56.71 \pm 13.87$ & $65.87 \pm 18.22$ \\
\hline BMl $\left(\mathrm{Kg} / \mathrm{m}^{2}\right)$ & $27 \pm 3$ & $21 \pm 4$ & $23 \pm 5$ \\
\hline Sex ratio $(\mathrm{M} / \mathrm{F})$ & $4 / 16$ & $8 / 12$ & $10 / 10$ \\
\hline Dialysis duration (months) & - & $12-60$ & $3-48$ \\
\hline Glucose $\left(\mathrm{g} . \mathrm{L}^{-1}\right)$ & $0.90 \pm 0.06$ & $0.85 \pm 0.02$ & $0.95 \pm 0.06$ \\
\hline Creatinin $\left(\mu \mathrm{mol} . \mathrm{ml}^{-1}\right)$ & $221 \pm 94$ & $834 \pm 47$ & $735 \pm 194$ \\
\hline Urea (mmol.L $\left.\mathrm{L}^{-1}\right)$ & $12 \pm 4$ & $14 \pm 1$ & $12 \pm 0.8$ \\
\hline Total proteins $\left(\mathrm{g} . \mathrm{L}^{-1}\right)$ & $66 \pm 0.6$ & $60 \pm 1.2$ & $57 \pm 0.9$ \\
\hline
\end{tabular}

Data are expressed in mean \pm SD. BMI: Body mass index (weight $\mathrm{kg} / \mathrm{height}$ $\mathrm{m}^{2}$ ). SBP: Systolic blood pressure, DBP: Diastolic blood pressure.

systemic disease such as diabetes, liver disorders and those affected by nephrotic syndrome. None of the patients were taking lipid-lowering drugs or antioxydant supplements. The drugs they were using included: calcium channel blockers, vit $\mathrm{D}$, calcium carbonate and erythropoietin. CRF patients included 20 subjects who had a mean value of creatinine clearance of $9.2 \pm 2.1$ $\mathrm{ml} / \mathrm{min}$ (range 5-13) as calculated from plasma creatinine according to Cockroft and Gault formula [16] $[$ GFR $=(140$-age $) \times$ body weight $\times 1.23 /$ creatinine. In women, this value was multiplied by 0.85 . Dietary protein and phosphate intake were restricted in these patients. HD patients were on standard bicarbonate HD using polysulfone membrane. Patients were dialyzed since 12 to 60 months, three times a week, each session lasting $4 \mathrm{~h}$. PD patients were in dialysis since 3 to 48 months, using a standard procedure (four exchanges: three isotonic $1.36 \%$ glucose solutions, then a hypertonic one at $3.86 \%$ glucose).

All patients were treated at the Nephrology ward of the University Hospital of Oran. The purpose of this study was explained to the subjects and the investigation was carried out with their consent. The experimental protocol was approved by the Committee for Research on Human Subjects of Oran.

\section{Assays}

In all patients, blood samples were drawn after a 12hours overnight fast by antecubital venipuncture in CRF and PD patients and by the dialysis fistule in HD patients. Samples were collected by low speed centrifugation at $3000 \times \mathrm{g}$ at $5^{\circ} \mathrm{C}$, for $15 \mathrm{~min}$, and were preserved with $0.1 \% \mathrm{Na} 2$ EDTA and $0.02 \%$ sodium azide.

\section{Lipids, proteins and apolipoproteins analysis}

Triacylglycerols (TG) and total cholesterol (TC) were determined by colorimetric methods (BioMérieux Kits, France). Plasma high density lipoprotein-cholesterol 
(HDL-C) was determined enzymatically using the CHOD-PAP kit after precipitation of the chylomicrons, very low density lipoprotein cholesterol and Low density lipoprotein cholesterol (LDL-C) with phosphotungstic acid and $\mathrm{Mg}^{++}$(BioMérieux Kits, SA-France). Plasma LDL-C was determined enzymatically using the CHOD-PAP kit after precipitation of LDL. Plasma apolipoproteins (apo) A-I and B were measured by immunoturbidimetric method (Human kit, Germany).

\section{Isolation of plasma VLDL-LDL-HDL 2 and $H D L_{3}$}

Lipoproteins were isolated by precipitation using $\mathrm{MgCl} 2$ and phosphotungstate (Sigma Chemical Company, France) by the method of Burstein et al., 1970 [17]. $\mathrm{HDL}_{2}$ and $\mathrm{HDL}_{3}$ were separated by precipitation according to the method of Burstein et al., 1989 [18] using $\mathrm{MgCl} 2$ and dextran sulfate weight 500,000 (Sigma Chemical Company, France).

\section{Lipid and protein peroxidation}

Lipid peroxidation was estimated by measuring thiobarbituric acid reactive substances (TBARS) concentrations according to the method of Quintanilha et al [19], using tetramethoxypropane (Prolabo) as precursor of malondialdehyde. TBARS was analyzed in plasma and in each lipoprotein. One milliliter of diluted sample (protein concentration about $2 \mathrm{mg} / \mathrm{ml}$ ) was added to $2 \mathrm{ml}$ of thiobarbituric acid (final concentration, $0.017 \mathrm{mmol} / \mathrm{L}$ ), butylated hydroxytoluene (concentration, $3.36 \mathrm{mmol} / \mathrm{L}$ ) and incubated for $15 \mathrm{~min}$ at $100^{\circ} \mathrm{C}$. After cooling and centrifugation, the absorbance of supernatant was measured at $535 \mathrm{~nm}$. Data were expressed as mmol of TBARS produced $/ \mathrm{ml}$ of plasma.

Oxidized proteins were estimated by measuring carbonyls concentrations according to the method of Levine et al [20] using the 2.4-dinitrophenylhydrazine (DNPH).

\section{Antioxidant measurements}

Superoxide dismutase (SOD; EC 1.15.1.1) and Glutathione peroxidase (GSH-Px; EC 1.11.1.9) were determined by Cayman Chemical kit. SOD activity was assessed at $440 \mathrm{~nm}$ by measuring the dismutation of superoxide radicals generated by xanthine oxidase and hypoxanthine. GSH-Px activity was measured indirectly by a coupled reaction with glutathione reductase (GRed). Oxidized glutathione (GSSG), produced upon reduction of an organic hydroperoxide by GSH-Px was recycled to its reduced state by G-Red and NADPH. The oxidation of NADPH to NADP + is accompanied by a decrease in absorbance at $340 \mathrm{~nm}$. Catalase (CAT; EC 1.11.1.6) activity was measured at $25^{\circ} \mathrm{C}$ using the Aebi method [21] by measuring the rate of decomposition of $\mathrm{H}_{2} \mathrm{O}_{2}$ at $240 \mathrm{~nm}$. Colorimetric methods were used for the determination of albumin, urate (Kits Boehringer, Mannheim, Germany), iron and bilirubin (Biolabo kit, France). C-Reactive Protein (CRP) was measured by the immunoturbidimetric method (Fumouze, France).

\section{Determination of plasma nitric oxide (NO)}

NO determination was performed using the Griess reagent (sulfamide and $n$-naphtyl-ethylene diamine) (Cortas \& Wakid., 1990) [22] method. Plasma was clarified by zinc sulfate sodium and $\mathrm{NO}_{3}$ was then reduced to $\mathrm{NO}_{2}$ by cadmium overnight at $20^{\circ} \mathrm{C}$ under shaking. Samples were added to the Griess reagent and incubated for $20 \mathrm{~min}$ at room temperature. Absorbance was measured at $540 \mathrm{~nm}$. Sodium nitrite was used for a standard curve.

\section{Statistical analysis}

Statistical analysis was performed using STATISTICA 6.0 (for windows, StatSoft Inc. software, Tulsa, OK, USA). Data are presented as mean \pm standard deviation (SD). Data normality and the distribution of the variables were tested by the Kolmogorov-Smirnov test. The difference between the means from the different groups was checked by ANOVA adjusted for multiple comparisons. Depending on the normality of distribution of variables, the comparisons between groups were performed using the unpaired Student's t-test, 1-way analysis of variance (ANOVA) or the Mann-Whitney U-test when results were nonparametrically distributed. $P<0.05$ was considered statistically significant.

\section{Results}

Lipids and apolipoproteins parameters (Table 2)

A significant decrease in TG values was noted in HD $(-52 \%)$ and PD $(-45 \%)$ compared to CRF $(\mathrm{p}<0.01)$, while no significant difference was noted. No significant difference was noted in TC values in HD and PD groups compared to CRF group. However, a significant decrease in $\mathrm{TC}$ values by $31 \%$ was noted in PD compared to HD $(\mathrm{p}<0.05)$.

Table 2 Lipids, apolipoproteins and atherogenic indices of the study groups

\begin{tabular}{|c|c|c|c|}
\hline & CRF & HD & PD \\
\hline $\mathrm{TG}\left(\mathrm{mmol} . \mathrm{L}^{-1}\right)$ & $3.11 \pm 0.4$ & $1.48 \pm 0.62^{* *}$ & $1.7 \pm 0.42^{* *}$ \\
\hline $\mathrm{TC}\left(\mathrm{mmol} . \mathrm{L}^{-1}\right)$ & $6.02 \pm 2.48$ & $6.82 \pm 1.29$ & $4.7 \pm 1.57$ \# \\
\hline HDL-C $\left(\mathrm{mmol}^{-L^{-1}}\right)$ & $1.29 \pm 0.94$ & $1.09 \pm 0.41$ & $1.07 \pm 0.53$ \\
\hline LDL-C $\left(m m o l . L^{-1}\right)$ & $2.25 \pm 0.62$ & $3.76 \pm 0.27^{* * \#}$ & $2.35 \pm 0.40$ \\
\hline Apo A-I $\left(g \cdot L^{-1}\right)$ & $1.07 \pm 0.53$ & $1.11 \pm 0.14$ & $0.89 \pm 0.48$ \\
\hline Apo B $\left(\right.$ g. $\left.L^{-1}\right)$ & $0.34 \pm 0.05$ & $0.27 \pm 0.07$ & $0.30 \pm 0.04$ \\
\hline $\mathrm{TC} / \mathrm{HDL}-\mathrm{C}$ & $7.38 \pm 0.34$ & $4.88 \pm 0.73 *$ & 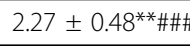 \\
\hline LDL-C/HDL-C & $2.50 \pm 0.94$ & $2.96 \pm 0.35$ & $2.59 \pm 1.36$ \\
\hline Apo Al/Apo B & $2.43 \pm 0.85$ & $3.89 \pm 0.67$ & $3.04 \pm 1.75$ \\
\hline
\end{tabular}

CRF: End stage chronic renal failure patients. HD: patients on hemodialysis. PD: Patients on peritoneal dialysis. Data are presented as the mean \pm SD. HD group and $P D$ group vs CRF group \# HD group vs $P D$ group. *\# $(P<0.05)$; **\#\#(P<0.01); \#\#\#(P<0.001) 
A significant increase by $40 \%$ in LDL-C values was observed in HD compared to CRF $(\mathrm{p}<0.01)$. Values were similar in PD and CRF. However, LDL-C concentrations were elevated by $37 \%$ in HD compared to $\mathrm{PD}$ $(\mathrm{p}<0.05)$.

Similar values of apo A-I, apo B, HDL-C concentrations, LDL-C/HDL-C and Apo AI/Apo B ratios were noted in HD, PD and CRF groups. However, values of TC/HDL-C ratio were decreased by $34 \%$ and $69 \%$, respectively in HD $(\mathrm{p}<0.05)$ and $\mathrm{PD}(\mathrm{p}<0.01)$, compared to CRF. Moreover, values of this ratio were diminished by $53 \%$ in PD compared to HD ( $<0.001$ ).

\section{Oxidative status (Table 3)}

Compared to CRF, TBARS values were elevated in HD $(\mathrm{P}<0.05)$ and $\mathrm{PD}(\mathrm{p}<0.05)$. A significant decrease in TBARS-VLDL by $82 \%$ and $95 \%$ was noted in HD and PD groups, respectively, compared to CRF group ( $\mathrm{p}<$ $0.01)$. TBARS-LDL were significantly higher in HD and PD groups compared to CRF group $(\mathrm{p}<0.05)$. There was no significant difference in TBARS- $\mathrm{HDL}_{3}$ values between the three groups. TBARS- $\mathrm{HDL}_{2}$ values were decreased by $48 \%$ and $74 \%$ in HD and PD, respectively, compared to CRF ( $\mathrm{p}<0.05)$. Values were more lower by $51 \%$ in PD compared to HD ( $\mathrm{p}<0.05)$.

Carbonyls values were significantly increased by $67 \%$ in HD $(\mathrm{p}<0.05)$ and by $84 \%$ in PD $(\mathrm{p}<0.01)$ compared to CRF. Carbonyls concentrations were more elevated $(+52 \%)$ in $\mathrm{PD}$ than in $\mathrm{HD}(\mathrm{p}<0.01)$.

\section{Antioxidative status (Table 4)}

Plasma SOD activity was decreased in HD compared to CRF $(-15 \%$; P < 0.05) and PD (-13\%; P < 0.05). Similar SOD activity was noted in PD and CRF. GSH-Px activity was decreased by $23 \%$ in HD and PD $(\mathrm{P}<0.005)$, compared to CRF. Decrease in catalase activity was noted only in PD compared to CRF $(-22 \% ; \mathrm{P}<0.05)$ and HD $(-18 \% ; \mathrm{P}<0.05)$. A significant increase by $26 \%$ in NO concentrations was noted in HD compared to CRF $(\mathrm{p}<0.05)$.

Table 3 Oxidative status in the study groups

\begin{tabular}{cccc}
\hline & CRF & HD & PD \\
\hline TBARS $\left(\mu \mathrm{mol} . \mathrm{L}^{-1}\right)$ & $0.12 \pm 0.01$ & $0.23 \pm 0.02^{*}$ & $0.18 \pm 0.01^{*}$ \\
\hline TBARS-VLDL $\left(\mu \mathrm{mol} . \mathrm{L}^{-1}\right)$ & $0.55 \pm 0.02$ & $0.10 \pm 0.05^{* *}$ & $0.026 \pm 0.014^{* *}$ \\
\hline TBARS-LDL $\left(\mu \mathrm{mol} . \mathrm{mL}^{1}\right)$ & $0.038 \pm 0.002$ & $0.055 \pm 0.023^{*}$ & $0.052 \pm 0.014^{*}$ \\
\hline TBARS-HDL $\left(\mu \mathrm{mol} . \mathrm{mL}^{1}\right)$ & $0.09 \pm 0.01$ & $0.047 \pm 0.008^{*}$ & $0.023 \pm 0.01^{* \#}$ \\
\hline TBARS-HDL $\left(\mu \mathrm{mol} . \mathrm{mL}^{1}\right)$ & $0.196 \pm 0.05$ & $0.105 \pm 0.070$ & $0.231 \pm 0.049$ \\
\hline Carbonyls $\left(\mu \mathrm{mol} . \mathrm{mL}^{1}\right)$ & $0.3 \pm 0.16$ & $0.92 \pm 0.15^{*}$ & $1.90 \pm 0.10^{* * \# \#}$ \\
\hline
\end{tabular}

CRF: End stage chronic renal failure patients. HD: patients on hemodialysis. PD: Patients on peritoneal dialysis. Data are presented as the mean \pm SD.

* HD group and PD group vs CRF group \# HD group vs PD group. $* \#(P<0.05)$; **\# $(P<0.01)$
Table 4 Antioxidative status in the study groups

\begin{tabular}{|c|c|c|c|}
\hline & CRF & HD & PD \\
\hline SOD $\left(U \cdot m^{-1}\right)$ & $82.10 \pm 1.53$ & $70.08 \pm 4.20^{*}$ & $80.12 \pm 0.38 \#$ \\
\hline GSH-Px $\left(U \cdot \mathrm{ml}^{-1}\right)$ & $5.92 \pm 0.53$ & $4.12 \pm 0.3^{*}$ & $4.08 \pm 0.06^{*}$ \\
\hline Catalase $\left(\right.$ U.ml $\left.{ }^{-1}\right)$ & $85.45 \pm 4.74$ & $80.18 \pm 1.32$ & $65.78 \pm 3.45^{* * \#}$ \\
\hline $\begin{array}{c}\text { Nitric oxide ( } \mu \text { mol.L' } \\
1 \text { ) }\end{array}$ & $22.53 \pm 7.24$ & $30.57 \pm 8.7^{*}$ & $20.52 \pm 1.58$ \\
\hline Albumins $\left(g \cdot L^{-1}\right)$ & $32.95 \pm 0.25$ & $30.78 \pm 1.18^{*}$ & $29.50 \pm 0.07^{*}$ \\
\hline Urate $(\mu \mathrm{mol} / \mathrm{L})$ & $\begin{array}{c}513.94 \pm \\
171.61\end{array}$ & $\begin{array}{l}382.09 \pm \\
66.07^{* * *}\end{array}$ & $\begin{array}{l}349.63 \pm \\
167.2^{* * *}\end{array}$ \\
\hline Bilirubin $(\mu \mathrm{mol} / \mathrm{L})$ & $6.29 \pm 2.60$ & $5.01 \pm 0.60$ & $8.39 \pm 6.76$ \\
\hline Iron $(\mu \mathrm{mol} / \mathrm{L})$ & $33.08 \pm 7.71$ & $55.17 \pm 1.53$ *** & $40.59 \pm 3.07 \# \# \#$ \\
\hline $\operatorname{CRP}\left(\mathrm{mg} \mathrm{L}^{-1}\right)$ & $6.5 \pm 0.2$ & $8.2 \pm 0.2^{*}$ & $8.8 \pm 0.8^{*}$ \\
\hline
\end{tabular}

CRF: End stage chronic renal failure patients. HD: patients on hemodialysis. PD: Patients on peritoneal dialysis. Data are presented as the mean \pm SD. ${ }^{*} \mathrm{HD}$ group and PD group vs CRF group \# HD group vs PD group. *\# $(\mathrm{P}<0.05) ; * *(\mathrm{P}<0.01)$; ***\#\#(P<0.001)

Albumin concentrations were diminished in HD and $\mathrm{PD}$ compared to CRF $(\mathrm{P}<0.05)$. Uric acid concentrations were decreased in HD and PD $(\mathrm{P}<0.001)$ compared to CRF. Bilirubin values were similar in the three groups. Whereas, an increase by $67 \%$ and $59 \%$ in iron values was noted in HD and PD, compared to PD ( $\mathrm{p}<0.001)$. CReactive Protein concentrations were higher in HD and PD groups compared to CRF $(\mathrm{p}<0.05)$.

\section{Discussion}

A comparative study was conducted in CRF patients, in order to evaluate the effect of HD and PD on lipid peroxidation, protein oxidation and antioxidant defence. The case-control studies agree that CRF patients have increased OS produced by an imbalance between proand anti-oxidant capacities [23-25]. This oxidative stress is responsible for the peroxidation of macromolecules such as lipids and proteins causing significant damage. Several pathophysiologic explanations have been claimed; some attribute it to malnutrition and hypoalbuminemia having in theses cases low availability of «thiol»; others to «uremic status» itself with solute retention that may favor their pathogenicity; and others to the association of comorbid factors such as advanced age, diabetes, and inflammatory and infectious phenomena [26,27].

Dyslipidemia is one of the main risk factors of cardiovascular complications in patients with CRF. In our study, patients on HD and PD have lower level of plasma triglycerides, than undialyzed CRF patients. Total cholesterol, HDL-C, apo A-I and B were unchanged according to dialysis treatment. However, HD causes an elevation of LDL-C. These results were different from our previous investigations in which we established more elevated TG values in HD patients treated by a cuprophan membrane [28]. 
The present study demonstrates that $\mathrm{HD}$ and $\mathrm{PD}$ cause an increase in oxidative stress. HD and PD leads to a lipid and protein peroxidation. OS was also affirmed by the decrease in the activity of antioxidant enzymes. Peroxidations of LDL have been postulated as important factors in the development of atherosclerosis. Increased levels of lipid peroxides are detected in patients with atherosclerotic disease. Also, the susceptibility of LDL to oxidation in vitro has been associated with the severity of coronary atheroselerosis in patients with CVD [29].

The formation of carbonyls is an early marker of protein oxidation. Carbonyls stress in uremia was related to decreased removal of chemically modified proteins by glomerular filtration. Reactive carbonyl compounds formed by the oxidation of carbohydrates and lipids may indirectly lead to advanced glycation or lipoxidation proteins, contributing to the long-term complications associated with CRF [30].

Free radicals are the source of lipid peroxidation derived from oxygen, and the first line of defense against them is SOD. Its function is to catalyse the conversion of superoxide radicals to hydrogen peroxide $\left(\mathrm{H}_{2} \mathrm{O}_{2}\right)$. Hence, the decreased SOD activity in HD suggests that the accumulation of superoxide anion radical might be responsible for increased lipid peroxidation [6]. Moreover, GSH-Px is responsible for most of the decomposition of lipid peroxide and may thus protect the cell from the deleterious effects of peroxides. $\mathrm{H}_{2} \mathrm{O}_{2}$ in the presence of sufficient catalase activity will be converted to harmless $\mathrm{H}_{2} \mathrm{O}$ and $\mathrm{O}_{2}$. In the present investigation, lower GSH-Px activity was observed in $\mathrm{HD}$ and PD. GSH-Px is an enzyme that scavenges $\mathrm{H}_{2} \mathrm{O}_{2}$ and lipid peroxides [6]. Our result explained the increase in TBARS levels. In this study, NO concentrations were elevated in HD patients however PD seems to not alter their levels. The important role of endothelial NO is the protection of the vascular wall from the OS induced by its own metabolic products and by the oxidation products of lipids and lipoproteins [14,15].

Bilirubin, uric acid and plasma albumin concentrations are the primary defense against $\mathrm{OS}$ in extracellular fluids results [30,31], generated during normal metabolism or introduced in the body by the consumption of dietary products rich in antioxidants. Knowing that our HD patients had a food intake characterized by reduced fruit and vegetables intake, this unbalanced diet contributes to a significant oxidative stress. Antioxidants are essentially made by fruit and vegetables that are rich in vitamins (A, C, E), trace - elements and other polyphenols.

The determination of plasma iron provides excellent guidance on the OS status of patients. Iron values were elevated in HD and PD patients. Iron plays a crucial role in the initiation and propagation of radical reactions allowing the formation of hydroxyl radicals $\left(\mathrm{OH}^{\circ}\right)$. Iron also catalyzes the decomposition of lipid peroxides $(\mathrm{ROOH})$ by transforming them into alkoxyl radicals ( $\mathrm{RO}$ $\left.{ }^{\circ}\right)$ and peroxyl $\left(\mathrm{ROO}^{\circ}\right)$ that amplify the process of lipid peroxidation. However, iron increase the generation of oxygen free radicals, leading to the formation of lipid peroxides [7]. In our study, CRP values were greater than $5 \mathrm{mg} . \mathrm{L}^{-1}$ in the CRF group and values were more elevated in HD and PD. CRP is a prominent product of the inflammatory response syndrome and a marker of overall and cardiovascular death in the general population as well as in CRF patients [32]. The view has been brought forward that a chronic inflammatory response may be the primary cause of increased oxidative stress in CRF patients [33]. However, it could also be vice versa. The imbalance between free radical formation and neutralization in dialysis patients may be the causative factor for the activation of an inflammatory cascade by a variety of potential stimulators in uremia and dialysis. A common signaling occurs via generation of oxygen-free radicals, activation of the transcription factor nuclear factor-kappa B (NF-B) and induction of a number of genes such as adhesion molecules, cytokines, and chemokines. The result may be IL- 6 stimulated production of CRP by the liver [32].

However, the problem to be addressed is to know why HD and PD aggravate oxidative stress of uremic patients. HD further worsens this condition mainly by losses of hydrophilic unbound small molecular weight substances such as vitamin $C$, trace elements and enzyme regulatory compounds. Moreover, inflammatory state plays a critical role in the production of oxidants contributing further to aggravate the pro-oxidant status of uremic patients $[7,8,30,31]$. Dialyser interactions and the microbial contamination or pyrogen content of the dialysate, the possible prooxidant effect of a number of metabolites, found at high concentrations in the patients' plasma, including uric acid have been suggested as the three major causes of OS. In the HD population, as the interaction between dialysis membranes and blood neutrophils can trigger the release of oxygen-free radicals and oxidizing agents, such as superoxide anion, hydrogen peroxide and myeloperoxidase. In turn, these molecules contribute to the oxidation of lipid by products, proteins and nucleic acids. This oxidation has several pathophysiological consequences, including enhanced atherogenicity of Ox-LDL, as well as accelerated demise of circulating erythrocytes, leading to a shorter life span [34,35].

Infections occurring in peritoneal dialysis patients are more frequent than in general population. Risk factors in those patients are multiple such as immune deficit and cutaneous port of entry. Our patients were treated by a conventional peritoneal dialysis considered as 
bioincompatible. Repeated and long-term exposure to conventional glucose-based peritoneal dialysis fluids plays a central role in the pathogenesis of the functional and structural changes of the peritoneal membrane. Low $\mathrm{pH}$, high glucose concentration and heat sterilization represent major factors of low biocompatibility [31]. GDP are formed during heat sterilization (glycoxidation) and storage. GDP can bind protein and form AGEs (Advanced Glycation End-products), which can also result from the binding of glucose to free $\mathrm{NH}_{2}$ residues of proteins (glycation).

In conclusion, this study demonstrates that hemodialysis and peritoneal dialysis exacerbate oxidative stress generated by uremia. HD and PD accentuate lipid and protein peroxidation, moreover, the activity of antioxidant enzymes was altered by both dialysis treatment

\section{Author details}

'Laboratoire de Nutrition Clinique et Métabolique, Département de Biologie, Faculté des Sciences, Université d'Oran 31100, Algérie. ${ }^{2}$ Service de Néphrologie, Etablissement Hospitalo-Universitaire d'Oran, Algérie.

\section{Authors' contributions}

KM: Study design, statistical analysis, results interpretation, literature search and drafting of the manuscript. WT: Data collection and biochemical analysis. NB: Biochemical analysis. AK: Data collection. MB: Manuscript preparation. All authors reviewed and approved the final version of the paper and approved of its submission to Lipids in Health and Disease.

\section{Competing interests}

The authors declare that they have no competing interests.

Received: 2 August 2010 Accepted: 3 September 2010

Published: 3 September 2010

\section{References}

1. Henrich WL: Optimal cardiovascular therapy for patients with ESRD over the next several years. Clin J Am Soc Nephrol 2009, 4(suppl I):S106-9.

2. Harper CR, Jacobson TA: Managing Dyslipidemia in Chronic Kidney Disease. Journal of the American College of Cardiology 2008, 51:2375-2384.

3. Chan DT, Irish AB, Dogra CK, Watts GF: Dyslipidaemia and cardiorenal disease: mechanisms, therapeutic opportunities and clinical trials. Atherosclerosis 2008, 196:823-834

4. Tsimihodimos V, Dounousi E, Siamopoulos KC: Dyslipidemia in chronic kidney disease: An approach to pathogenesis and treatment. American Journal of Nephrology 2008, 28:958-973.

5. Annuk M, Zilmer M, Fellstro B: Endothelium-dependent vasodilation and oxidative stress in chronic renal failure: Impact on cardiovascular disease. Kidney International 2003, 63:S50-S53.

6. SIES H: Oxidative stress: oxidants and antioxidants. Exp Physiol 1997, 82:291-295.

7. Locatelli F, Canaud B, Eckardt KU, Stenvinkel P, Wanner C, Zoccali C Oxidative stress in end-stage renal disease: an emerging threat to patient outcome. Nephrol Dial Transplant 2003, 18:1272-1280.

8. Lucchi L, Bergamini S, lannone A, Perrone S, Stipo L, Olmeda F, Caruso F, Tomasi A, Albertazzi A: Erythrocyte Susceptibility to Oxidative Stress in Chronic Renal Failure Patients Under Different Substitutive. Treatments Artif Organs 2005, 29:67-72.

9. Rutkowski P, Malgorzewicz S, Slominska E, Renke M, Lysiak-Szydlowska W, Swierczynski J, Rutkowski B: Interrelationship Between Uremic Toxicity and Oxidative Stress. Journal of Renal Nutrition 2006, 16:190-193.

10. Ramos R, Martinez-Castelao A: Lipoperoxidation and hemodialysis. Metabolism: Clinical and Experimental 2008, 57:1369-1374.
11. Suresh DR, Delphine $S$, Agarwal R: Biochemical markers of oxidative stress in predialytic chronic renal failure patients. Hong Kong Journal of Nephrology 2008, 10:69-73.

12. Müller-Krebs S, Kihm LP, Zeier B, Gross ML, Wieslander A, Haug U, Zeier M, Schwenger V: Glucose degradation products result in cardiovascular toxicity in a rat model of renal failure. Perit Dial Int 2010, 30(1):35-40.

13. Tarng DC, Wen Chen T, Huang TP, Chen CL, Liu TY, Wei YH: Increased Oxidative Damage to Peripheral Blood Leukocyte DNA in Chronic Peritoneal Dialysis Patients. J Am Soc Nephrol 2002, 13:1321-1330.

14. De Deyn PP, Vanholder R, D'hooge R: Nitric oxide in uremia: effects of several potentially toxic Guanidino compounds. Kidney International 2003, 63:S25-S28.

15. Zweier JL, Li H, Samouilov A, Liu X: Mechanisms of nitrite reduction to nitric oxide in the heart and vessel wall. Nitric Oxide 2010, 15; 22(2):83-90.

16. Trollfors B, Alestig K, Jagenburg R: Prediction of glomerular filtration rate from serum creatinine, age, sex and body weight. Acta Med Scand 1987, 221:495-508

17. Burstein M, Scholnick HR, Morfin R: Rapid method for the isolation of lipoproteins from human serum by precipitation with polyanions. J Lipid Res 1970, 11:583-595.

18. Burstein M, Fine A, Atger V, Wirbel E, Girard-Globa A: Rapid method for the isolation of two purified subfractions of high density lipoproteins by differencialdextran magnesium chloride precipitation. Biochemistry 1989, 71:741-746.

19. Quintanilha AT, Packer L, Davies JM, Racanelli TL, Davies KJ: Membrane effects of vitamin E deficiency: bioenergetic and surface charge density studies of skeletal muscle and liver mitochondria. Ann N Y Acad Sci 1982, 393:32-47.

20. Levine RL, Garland D, Oliver CN, Amici A, Climent I, Lenz A, Ahn BW, Shaltiel S, Stadtman ER: Determination of carbonyl content in oxidatively modified proteins. Methods Enzymol 1990, 186:464-478.

21. Aebi H: Catalase. In Methods of Enzymatic Analysis. Edited by: Berg Meyer H. Verlag Chemie, Weinheim, Germany; , Second 1974:673-684.

22. Cortas N, Wakid N: Determination of inorganic nitrate in serum and urine by kinetic cadmium-reduction method. Clin Chem 1990, 36:1440-43.

23. Dirican M, Sarandol E, Serdar Z, Ocak N, Dilek K: Oxidative status and prevalent cardiovascular disease in patients with chronic renal failure treated by hemodialysis. Clinical Nephrology 2007, 68:144-150.

24. Pawlak K, Pawlak D, Mysliwiec M: Possible association between circulating vascular endothelial growth factor and oxidative stress markers in hemodialysis patients. Med Sci Monit 2006, 12(4):CR181-5.

25. González Rico M, Puchades MJ, García Ramón R, Saez G, Tormos MC, Miguel A: Effect of oxidative stress in patients with chronic renal failure. Nefrologia 2006, 26(2):218-25.

26. Miyata T, Kurokawa K, van Ypersele de Strihou C: Relevance of oxidative and carbonyl stress to long-term uremic complications. Kidney Int Suppl 2000, 76:5120-5.

27. Maritim AC, Sanders RA, Watkins JB: Diabetes, oxidative stress, and antioxidants: a review. J Biochem Mol Toxicol 2003, 17:24-38.

28. Mekki K, Bouchenak M, Remaoun M, Belleville JL: Effect of long-term hemodialysis on plasma lecithin: cholesterol acyltransferase activity and the amounts and compositions of HDL2 and HDL3 in hemodialysistreated patients with chronic renal failure: a 9-year longitudinal study. Med Sci Monit 2004, 10(8):CR439-46.

29. Sutherland WH, Walker RJ, Ball MJ, Stapley SA, Robertson MC: Oxidation of low density lipoproteins from patients with renal failure or renal transplants. Kidney Int 1995, 48(1):227-36.

30. Valko M, Rhodes CJ, Moncol J, Izakovic M, Mazur M: Free radicals, metals and antioxidants in oxidative stress induced cancer. Chem Biol Interact 2006, 160:1-40

31. Rahman, Adcock IM: Oxidative stress and redox regulation of lung inflammation in CAPD. Eur Respir J 2006, 28:219-242.

32. Wanner C, Zimmermann J, Schwedler S, Metzger T: Inflammation and cardiovascular risk in dialysis patients. Kidney International 2002, 61: S99-S102.

33. Stenvinkel P: Endothelial dysfunction and inflammation: Is there a link? Nephrol Dial Transplant 2001, 16:1968-1971.

34. Malliaraki N, Mpliamplias D, Kampa M, Perakis K, Margioris AN, Castanas E: Total and corrected antioxidant capacity in hemodialyzed patients. BMC Nephrology 2007, 4:4. 
35. Sosa MA, Balk EM, Lau J, Liangos O, Balakrishnan VS, Madias NE, Pereira BJ, Jaber BL: A systematic review of the effect of the Excebrane dialyser on biomarkers of lipid peroxidation. Nephrol Dial Transplant 2006, 21:2825-2833.

doi:10.1186/1476-511X-9-93

Cite this article as: Mekki et al.: Effect of hemodialysis and peritoneal dialysis on redox status in chronic renal failure patients: a comparative study. Lipids in Health and Disease 2010 9:93.

Submit your next manuscript to BioMed Central and take full advantage of:

- Convenient online submission

- Thorough peer review

- No space constraints or color figure charges

- Immediate publication on acceptance

- Inclusion in PubMed, CAS, Scopus and Google Scholar

- Research which is freely available for redistribution

Submit your manuscript at www.biomedcentral.com/submit
C Biomed Central 